\title{
Does an Interdisciplinary Network Improve Dementia Care? Results from the IDemUck-Study
}

\author{
Leonore Köhler ${ }^{1}$, Claudia Meinke-Franze ${ }^{2}$, Jürgen $\mathrm{Hein}^{3}$, Konstanze Fendrich ${ }^{2}$, Romy Heymann ${ }^{4}$, \\ Jochen René Thyrian ${ }^{1, *}$ and Wolfgang Hoffmann ${ }^{1,2}$
}

\begin{abstract}
${ }^{1}$ German Centre for Neurodegenerative Diseases (DZNE) Greifswald, Ellernholzstrasse 1-2, Greifswald, D-17489, Germany; ${ }^{2}$ Section Epidemiology of Health Care and Community Health, Institute for Community Medicine, Ernst-Moritz-Arndt-University, Ellernholzstrasse 1-2, Greifswald, D-17489, Germany; ${ }^{3}$ Dementia Network Uckermark, Rosa-Luxemburg-Strasse 21, Prenzlau D-17291, Germany; ${ }^{4}$ Institute for Health Care Management and Research, University Duisburg-Essen, Schützenbahn 70, D-45127 Essen, Germany
\end{abstract}

\begin{abstract}
Background: Most persons with dementia live at home and are treated in the primary care. However, the ambulatory health care system in Germany contains a lot of "interface problems" and is not optimized for the future challenges. Innovative concepts like regional networks in dementia care exist on a project level and need to be tested for efficacy to encourage implementation. The goal of the study is the scientific evaluation of an already existing regional dementia network. Methods: Prospective randomized controlled trial of 235 community-living elderly with dementia and their family caregivers of network treatment $(n=117)$ compared to usual care $(n=118)$ in a predominantly rural region. The allocation to intervention or control group was based on network membership of their General Practitioner. Intervention patients received diagnostic evaluation and subsequent treatment according to network guidelines. Main outcome measures were the early contact with a neurologic or psychiatric specialist and dementia-specific medication as well as quality of life of the patients, and as secondary outcomes caregiver burden and caregiver health-related quality of life. Results: Network patients were more likely to receive antidementive drugs $(50.5 \%$ vs. $35.8 \% ; \mathrm{p}=0.035)$ and had more often contact to a neurologist $(18.6 \%$ vs. $2.8 \%$; p $<0.001)$. No group differences were found on patient's quality of life nor overall effects or treatment by time effects. Intervention caregivers reported no significant improvements in health related quality of life measured by SF-36 and EQ-5D. Conclusion: The management of dementia patients in an interdisciplinary regional network solelyprovides measurable advantages with respect to the provision of dementia-specific medication and utilization of medical treatment i.e. referral rates to specialists. Further evaluation research is needed to identify relevant mechanismsof collaborative processes with respect to their impact on patient and caregiver related outcomes.
\end{abstract}

Keywords: Collaborative care, dementia, disease management, intervention study, primary care.

\section{INTRODUCTION}

In Germany, similar to many industrialized societies, the adequate diagnosis and treatment of dementia as well as the appropriate care will become more and more important. Based on reimbursement data from statutory health insurances, the number of people diagnosed with moderate or severe dementia in 2007 in Germany was estimated to be approximately 1.1 million people [1]. The number of people affected by dementia is anticipated to grow up exponentially as population age [2]. Due to its maximum prevalence at a very old age dementia has been described as the disease with the steepest increase among chronic illnesses due to the demographic change [3, 4]. Because of rising life expectancy, the prevalence of dementia is expected to further increase over the next decades. Dementia is becoming a great challenge to health and social services and will have serious consequences on many areas of society [5]. Caring for

*Address correspondence to this author at the German Centre for Neurodegenerative Diseases (DZNE) Greifswald, Ellernholzstrasse 1-2, Greifswald, D-17489, Germany; Tel: +49 3834 86-7592; Fax: +49 3834 86-19551;

E-mail rene.thyrian@dzne.de people with dementia will become an everyday task in the professional sphere and in people's private lives.

In Germany like in other industrialized countries most people with dementia living in their home environment receiving care from family caregivers $[6,7]$. German society and the health policy emphasize caring for highly dependent older people at home as long as possible. Yet dementiarelated morbidity imply a complex interdisciplinary and multi-professional treatment, which needs not just to focus on the person with dementia but also to consider caregiver relatives and the individual's social environment. The health care system is not yet attuned to this challenge. Dementia only came into focus in medical and nursing care in recent years. Research into non-pharmacological treatment and integrated care, especially for people living at home, is scarce [8]. While the health care system in principle offers all necessary forms of treatment and care, there is no systematic coordination in the complex and sectorized German health system [9].

To resolve these "interface problems," a variety of "dementia networks" have been implemented in pilot projects throughout Germany [10]. The "Leuchtturm projekte De- 
menz" (Lighthouse Projects Dementia) was initiated by the Federal Ministery of Health to remedy the lack of scientific evidence in dementia care research. One of the most pressing areas was the qualitative and quantitative evaluation of care structures. The IDemUck-study was one of the wider projects funded in this area. IDemUck is an acronym for "Interdisciplinary Care and Treatment network for people with Dementia in the Uckermark", a rural administrative district in the north-east of Germany. The goal of the study was the quantitative evaluation of an already-existing dementia network.

\section{The Network}

The Uckermark is a predominantly rural area in the federal state of Brandenburgin Eastern Germany. Emigration and a negative balance in population growth produced a rapidly aging population. Local medical care is affected by an impending under-supply with general practitioners, specialists located in the city regions and long distances in between. In this context an interdisciplinary dementia network has been established since its initiation in 2004. The differentiating characteristic of this network is its integrative organization across medical disciplines, various professions and stakeholders in outpatient medical care, and a straight through sectoral boundaries in health care system: members include general practitioners (GP) and medical specialists, social workers, hospitals, and other outpatient and inpatient settings. In 2009 the network comprised 46 practitioners (general medicine and specialists for psychiatry or neurology), two hospitals and about 20 medical and social institutions.

In the network, GP's have the option to immediately become a full member or at first become an associated member. A full member commits oneself to participate in common qualification courses. No financial costs arise for a membership in the network, members participate on a voluntary base and most of the organizational tasks are performed as unpaid extra work in the members' spare time.

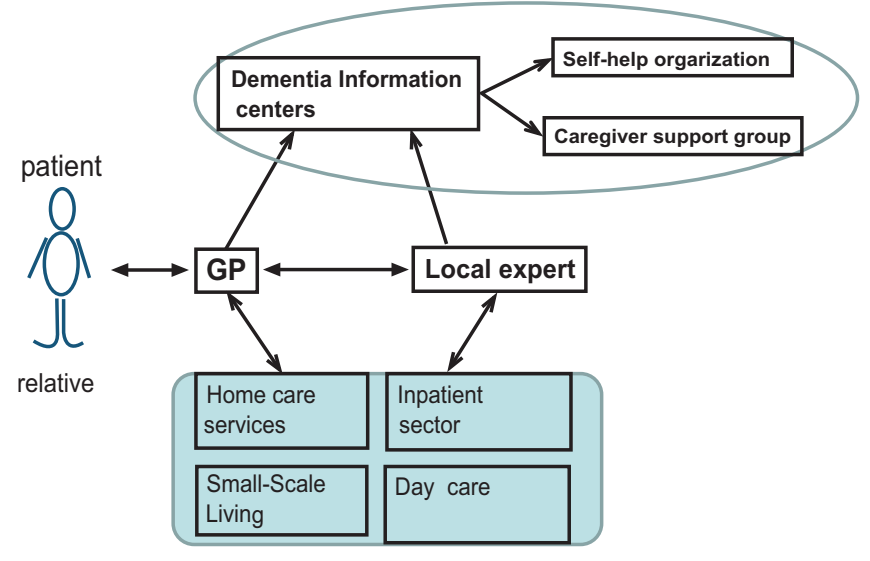

(source: Demenz-Netzwerk Uckermark e.V.)

Fig. (1). Structured treatment paths in Dementia network.

\section{Goals and Algorithms}

The general goal agreed on by all network partners was to better organize and provide care and treatment for people with dementia according to structured treatment paths. To meet the requirements of dementia care the network was structured in two acting levels in accordance with the fundamental network targets: to confirm an early diagnosis and differential diagnostics (A) and to deliver a person-centred and comprehensive therapy over the course of the disease (B). The GP assumed the role of the gatekeeper in the network. He ascertains a semi-standardized medical history, conducts a standardized neuropsychological screening test and if necessary recommends consultations with various specialists inside the network (level A). The GP collects all diagnostic findings and monitors the course of treatment (level B). Neurologists and psychiatrists are classified as the local experts in the network. If a patient is referred to them by the gatekeeper, the local specialist completes a diagnostic workup (including imaging and biomarker analysis), compiles all findings, evaluates the diagnosis against differential diagnosis and refers the patient back to the GP. Only unclear or particularly severe cases should be transferred to the memory clinic or as in-patients to the hospital. Clinics and the hospitals are considered as centers of excellence that provide advanced diagnostics, including invasive diagnostics (e.g., lumbar punctures) and coordinate other specialized facilities on level A.

In the course of disease the GP offers first access and successive admission to health and social services and treatment (Level B). Local expert assumes the ambulatory treatment only in complicated cases with psychiatric comorbidity. Centers of excellence provide an individualized crisis intervention thereby using comprehensive data available for most network patients.

The participating patients with dementia should benefit from the network personally with regard to their ability to live independently, and to remain socially included. With regard to patient care they should benefit from continuous medical care and a minimization of unscheduled hospitalizations.

This present analysis is part of the evaluation and examines the network efficacy regarding (a) a definite diagnosis via expert consultation,(b) the utilization of medical treatment and care, (c) the dementia-specific medication, (d) the quality of life of the patients, and (e) the caregiver burden and health-related quality of life (secondary outcome).

\section{METHODS}

The evaluation study was designed as a prospective controlled intervention trial.

The recruitment procedure took place in medical practices, hospitals and in social and home care services. Eligible participants were (a) 55 years or older, (b) lived in the study area of the Uckermark and (c) had a positive screening in the DemTect $($ score $<9$ ) [11] and no hint for severe depression (Geriatric Depression Scale $<11$ ). Persons living in residential care were excluded as well as such not being able to participate due to severe sensory impairment, or limited command of German language. Previously diagnosis of dementia did not prevent study participation.

Practitioners, medical and social services were invited to screen for persons with probably dementia to participate. Eligible patients were allocated to intervention or control 
group by the current status of their attending physician as a full member and associated member of dementia network, respectively. Assigned to the intervention group patients were treated according to defined algorithms in collaborative care while the control group received medical care as usual.

Assuming a power of $80 \%$ and an alpha of 5\% an expected medium effect for some outcome parameter required a sample size of 225 individuals. In 38 participating medical practices and care providers $\mathrm{N}=457$ patients could be screened. 285 persons $(62.4 \%)$ were screened positive, 25 persons had to be excluded due to sensory impairment, and severe illness. From the sample eligible $\mathrm{n}=235$ patients $(90.4 \%)$ participated in the study, $\mathrm{n}=117$ were allocated to the intervention group and $n=118$ to the control group. After providing written informed consent the participating patient was asked for a caring relative and wherever applicable, this person was asked for participation, too.

Then, study staff conducted a standardized baseline assessment including sociodemographical characteristics, health-related quality of life assessments (Quality of life in Alzheimer's disease Qol-AD [12], EQ-5D [13], Short Form36 Health Survey SF-36 [14]), Activities of daily living (IADL [15], NAA [16]), and caregiver burden (BIZA-D [17]). Severity of cognitive impairment was identified by using Mini Mental State Examination ('none' 30-27, 'mild' 26-21, 'moderate'20-11 and 'severe' 10-0)[18]. Data regarding the utilization of medical treatment and pharmacotherapy were obtained from the caregivers, and if not available, from the person with dementia. To assess the actual home medication situation the trade name of presented medicaments were listed and classified by a study pharmacist. Analysis of dementia-specific pharmacotherapy focused on the following substances in accordance with the current primary care guideline [19]: donepezil, galantamine, rivastigmine and memantine.

About six to twelve months later the dementia patients and their caregivers were contacted a second time and the same assessments were conducted. A total of $86.4 \%$ of baseline patients attended the follow-up. For half of the patients under network treatment this check took place approximately one year after first questioning (median 11.2, range 5.5 - 12.9 month). Patient in the care as usual group predominantly were assessed six month after baseline (median 6.6, range $5.6-$ 13.6 month). In the course of the study, 11 participants $(9.4 \%)$ from the care as usual unit and 21 participants $(17.8 \%$ ) from the network care unit dropped out, mostly because of death $(40 \%)$. Eleven patients in the intervention group could not be assessed a second time due to withdrawn consent. In the average the drop-outs were associated with upper age and more serious cognitive impairment.

The Data collection was conducted between September 2008 and February 2010 applying Computer aided Personal Interviews (CAPI). The study design was approved by the Ethics Committee of the Medical Faculty of Ernst-MoritzArndt-University Greifswald.

\section{Statistical Analysis}

Inter- and intra-group distributions are compared using T-test (comparison of means), McNemar-test (contingency tables with pairing) and Pearson's chi-square test (categorical variables). A series of repeated measurement analysis of variance (ANOVA) were performed to examine whether the network based treatment and the care as usual produce significant changes on the pre-defined outcome criteria. Structural differences between groups were accounted for by additionally adjusting for age and gender. The analyses were conducted using SAS software (version 9.03; SAS Institute, Cary, NC) and SPSS (version 17; IBM SPSS Statistics, NY).

\section{RESULTS}

The $\mathrm{n}=235$ participants in IDemUck had a mean age of $78.3(\mathrm{SD}=7.74)$ years and $33.2 \%$ of them were male. The mean age was significantly higher in females ( 80.0 years) than in males $(74.8$ years; $p<0.001)$. Approximately half of the participating patients were married or lived in a relationship $(46.4 \%), 43.8 \%$ were widowed. $79 \%$ referred to an informal caregiver, in the main a spouse $(40.3 \%)$ or a child $(39.8 \%)$. The proportion of offspring caregivers in the care as usual group is slightly higher than in the intervention group however this tendency did not reach statistical significance (Table 1).

Looking at education profiles, most participants achieved a secondary school level $(65.1 \%)$ of 10 years, just $3 \%$ finished 12-13 years of formal education, and $12.3 \%$ of the patients had no final certificate. One-third had completed an apprenticeship and39\% \% not received professional training. Based on the specifications of school and occupational qualification, last occupational position and present net income a class index was calculated [20]. According to this algorithm among 178 categorized patients $86.5 \%$ belong to the lower social class, $11.2 \%$ to a middle social class and $2.3 \%$ to an upper social stratum.

Among the informal caregivers $72 \%$ were female and only a minority $(6 \%)$ was younger than forty years. The average age was 60.5 years, male caregivers were significantly older (64.7; $\mathrm{SD}=14.9)$ then the females (58.9, $\mathrm{SD}=12.3 ; \mathrm{p}=0.007)$. Male caregivers were mostly spouses $(60.4 \%)$, while among the female relatives were more children $(48 \%)$ and less spouses $(36.2 \%)$. Most caregivers lived in close relationship $(76.9 \%)$, but the proportion of singles was higher among female $(26.1 \%)$ than male caregivers $(15.4 \%)$.

Care receiver and caregiver characteristics at baseline for each of the study groups are shown in (Table 1). The characteristics did not differ significantly between the groups receiving network care and care as usual.

\section{Cognitive Functioning}

The average MMSE-score was to $18.9(\mathrm{SD}=5.9)$ indicating predominantly mild to moderate dementia. In this sample38 \% of persons with probably dementia (PwD) were categorized as 'mild dementia', $43.4 \%$ as 'moderate dementia', and $9.4 \%$ as 'severe dementia'. Also 14 positive screened participants $(6 \%)$ were included classified as 'no hint for dementia' according to the MMSE status.

The caregivers, family or professional, were asked for a known medical diagnosis of dementia and 147 responses 


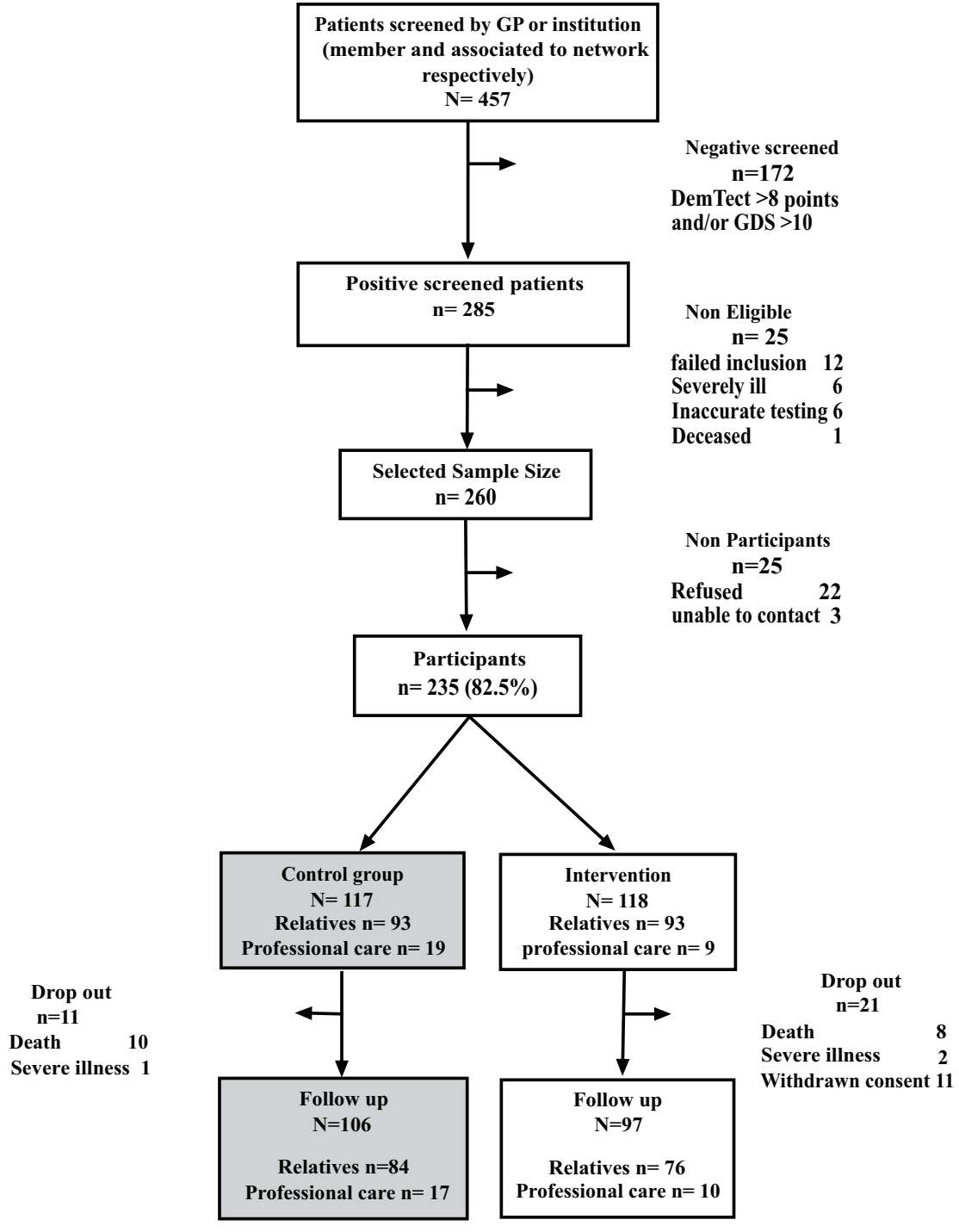

GDS= Geriatric Depression Scale

Fig. (2). Flow-chart of the study population.

were available. A diagnosis previous to evaluation has been reported for $32 \mathrm{PwD}$ in the intervention group and $24 \mathrm{PwD}$ in the control group.

\section{Physical Functioning and Autonomy of Patient}

The persons with dementia rated their competences and constraints in daily activities with the Nuremberg AltersAlltags-Skala (NAA). The scale adds up to a score between 20 and 60 points with the higher values indicating greater restrictions. In the average the patients reached 37.4 points $(\mathrm{SD}=7.88)$. In all age groups the IDemUck care receivers showed statistical significant higher constraints $(p<0.01)$ than the norm values based on a representative sample of community dwelling elderly [14]. Increasing severity of dementia is associated with reported greater limitations in the daily activities (e.g. for mild dementia mean $=34.9$ and for severe dementia mean $=42.3$, respectively) $(\mathrm{F}=7.274$; $\mathrm{p}<0.001)$.
The informal or professional caregiver rated functional competence using the Instrumental Activities of Daily Living. On a $0-8$ point scale, with higher values representing a higher degree of autonomy, more than half of the rated patients $(51.9 \%)$ get a maximum of two points. Patients with mild dementia scored an average level of $3.7(\mathrm{SD}=2.2)$ and patients with severe dementia of $1.0(\mathrm{SD}=1.1)$, respectively. Similarly increasing severity of dementia is accompanied by a distinct decline in patient's autonomy in caregiver rating.

Neither in self-rating nor in the proxy scale the average level of activities of daily living made a distinction between intervention and control group at baseline (s. Table 1).

\section{Outcome Measures}

\section{Prerequisites of Patient's Autonomy}

In question of cognitive capability the second time testing revealed a small distinction between the two study 
Table 1. Description of the sample population at baseline.

\begin{tabular}{|c|c|c|c|}
\hline PATIENT CHARACTERISTICS & $\mathrm{N}=118$ & $\mathrm{~N}=117$ & \\
\hline male & $44(37.3)$ & $34(29.1)$ & \\
\hline female & $74(62.7)$ & $83(70.9)$ & \\
\hline $55-64$ & $3(2.5)$ & $8(6.8)$ & 0.147 \\
\hline $65-74$ & $34(28.8)$ & $25(21.4)$ & \\
\hline $75-84$ & $64(54.2)$ & $59(50.4)$ & \\
\hline married/partnership & $60(50.8)$ & $49(42.2)$ & \\
\hline divorced & $9(7.6)$ & $4(3.4)$ & \\
\hline widowed & $46(39.0)$ & $57(49.1)$ & \\
\hline Level of education, n (\%) & & & 0.123 \\
\hline Without graduation & $15(12.7)$ & $14(12.0)$ & \\
\hline Secondary general school certificate & $84(72.1)$ & $69(59.0)$ & \\
\hline Secondary extended certificate and higher & $10(8.5)$ & $17(14.5)$ & \\
\hline Moderate (20-11) & $52(44.1)$ & $50(43.5)$ & \\
\hline Severe $(<11)$ & $10(8.5)$ & $12(10.3)$ & \\
\hline None & $11(9.3)$ & $3(2.6)$ & \\
\hline Transfer of care insurance, $\mathrm{n}(\%)$ & & & 0.493 \\
\hline Yes & $62(56.4)$ & $70(64.2)$ & \\
\hline No & $42(38.2)$ & $34(31.2)$ & \\
\hline Applied for & $6(5.5)$ & $5(4.6)$ & \\
\hline CAREGIVER CHARACTERISTICS & $\mathrm{N}=93$ & $\mathrm{~N}=93$ & \\
\hline Gender, n (\%) & & & 0.191 \\
\hline Male & $30(32.3)$ & $22(23.7)$ & \\
\hline female & $63(67.7)$ & $71(76.3)$ & \\
\hline Mean Age, years (SD) & $61.4(13.2)$ & $59.7(13.5)$ & 0.384 \\
\hline$<65$ years, $\mathrm{n}(\%)$ & $52(55.9)$ & $61(65.6)$ & 0.177 \\
\hline 65years and older, $\mathrm{n}(\%)$ & $41(44.1)$ & $32(34.4)$ & \\
\hline
\end{tabular}


(Table 1) contd....

\begin{tabular}{|c|c|c|c|}
\hline Type of Relationship, n (\%) & & & 0.399 \\
\hline Offspring $^{1}$ & $41(44.0)$ & $49(52.7)$ & \\
\hline Others or not specified & $10(10.8)$ & $11(12.8)$ & \\
\hline employed & $23(24.7)$ & $20(21.5)$ & \\
\hline unemployed & $7(7.5$ & $6(6.5)$ & \\
\hline retired & $35(37.6)$ & $29(31.2)$ & \\
\hline
\end{tabular}

1 including child, grandchild and some child-in-law, 2 p-value was conducted using chi-squaretestin categorical and two-tailed t-test in continuous variables $\mathrm{SD}$, Standard deviation.

groups. The mean difference between first and second testing in the intervention group was -0.7 (95\% CI -1.5, 0.1; $\mathrm{p}=0.009$ ) and is not considered to worsen. The second testing of PwD allocated to the control group indicated a statistically significant decline in cognitive function (mean $=-1.4(95 \% \mathrm{CI}$ $-2.1,0.7) ; \mathrm{p}<0.001)$. The rate of a decline with more than two points in MMSE-score amount to $27.8 \%$ and $32.7 \%$ for the intervention and the control group, respectively. However, the interaction of time and treatment revealed no significant intervention effect $(\mathrm{F}=1.6 ; \mathrm{p}=0.205)$.

In both study arms self-rated competences and constraints in daily activities did not indicate increasing restrictions. The reported differences in the intervention group add up to 0.9 points $(95 \% \mathrm{CI}-0.1,1.9 ; \mathrm{p}=0.075)$ and in the control group the result was 0.5 points less in average $(95 \% \mathrm{CI}$ $0.5,1.5 ; \mathrm{p}=0.310$ ). In contrast, proxys judged the current competence as inferior to first time evaluation. The IADLscore declined in average 0.3 points $(95 \% \mathrm{CI}-0.7,0.0$; $\mathrm{p}=0.063)$ and 0.5 points $(95 \% \mathrm{CI}-0.8,-0.2 ; \mathrm{p}=0.001)$ in the intervention group and the control group, respectively. Between the study arms differences were not statistically significant $(\mathrm{F}=0.6, \mathrm{p}=0.448)$.

\section{Utilization of Medical Treatment and Care}

Approximately half of the persons with dementia reported regular consultations with a GP in the 6 months prior to assessment. This proportion was slightly higher, but not significant different, in the intervention group than in the routine care group $(55.7 \%$ vs. $45.3 \%$; $=0.317)$. Contact with a specialist, i.e. a neurologist, however, had significant more often patients recruited by network members both at baseline ( $28.9 \%$ vs. $4.7 \%)$ and at follow-up (18.6 \% vs. 2.8 $\% ; \mathrm{p}<0.002$ ) (Table 2). This difference was conserved at baseline and at follow-up (21.3\% vs. $8.5 \%$; $\mathrm{p}=0.046)$ excluding a subsample from analysis screened by a specialist. Giving PwD without a reported previous diagnosis of dementia attention as if they had just enrolled the utilization rate at follow-up changed to $25 \%$ vs. $2.4 \%$ in intervention and control group, respectively. Distinguishing between severity of dementia, the contact with a specialist was signifi- cantly higher for network treated patients solely with no and mild dementia.

Frequencies of contacts to other specialists or for rehabilitation measures did not differ between the groups. The utilization of occupational therapy and other therapy or a day clinic was generally very low, with no difference between intervention and control patients.

\section{Dementia-Specific Medication}

Anti-dementia drugs were more frequently prescribed to those in the intervention group than to those in the control group. There was an overall increase in frequency of being treated with anti dementive drugs from $34 \%$ to $50.5 \%$ $(p \leq 0.001)$ between baseline and follow-up. Close to $30 \%$ of the intervention group received antidementive medication for the first time between baseline and follow-up. $9.1 \%$ of intervention patients no longer received antidementive drugs at follow-up. The therapy was finished in $11.8 \%$ of the patients with moderate dementia and $20 \%$ of the persons with severe dementia.

In the control group prescription of antidementive drugs was stable between baseline and follow-up (34 \% vs. $35.8 \%$ ). The proportion of the PwD being treated for the first time with antidementive drugs was $11.4 \%$. However in $25 \%$ of the persons with mild dementia and $10.5 \%$ of the moderate dementia prescription changed or stopped between baseline and follow-up, which related to $16.7 \%$ of all patients in the control arm at follow-up.

Further analyses sensitive to treatment time however revealed that with a longer period between baseline and follow-up the differences in prescription of antidementive drugs between control group and intervention group decreased.

\section{Patient's Quality of Life}

Baseline scores for Qol-AD were comparable for patients treated in network algorithm and care as usual. There was no change over time in health-related quality of life, $(\mathrm{F}=0.320$; $\mathrm{p}=0.572$ ), neither in the intervention nor in the control group. The average score was $33.9(\mathrm{SD}=5.6)$ and $33.7(\mathrm{SD}=5.7)$, 
Table 2. Variance in outcome criteria by time and group: proportion, analysis of variance, significance.

\begin{tabular}{|c|c|c|c|c|c|c|c|}
\hline & \multicolumn{2}{|c|}{$\begin{array}{c}\text { Intervention } \\
\quad \mathbf{N}=\mathbf{9 7}\end{array}$} & \multicolumn{3}{|c|}{$\begin{array}{c}\text { Control group } \\
\quad \mathrm{N}=106\end{array}$} & & \\
\hline Source of variance & BL & FU & BL & FU & & & \\
\hline PATIENT & & & & & $p$ & & \\
\hline General Practitioner (\%) & 90.7 & 55.7 & 74.5 & 45.3 & 0.317 & & \\
\hline Psychiatrist / psychotherapist (\%) & 11.3 & 3.1 & 17.0 & 8.5 & .083 & & \\
\hline Casualty (\%) & 16.5 & 1.0 & 13.2 & 0.0 & & & \\
\hline Hospital (\%) unscheduled & 29.9 & 5.2 & 26.4 & 3.8 & 0.673 & & \\
\hline \multicolumn{8}{|l|}{ Therapy } \\
\hline Day care $(\%)$ & 0 & 1.0 & 3.8 & 3.8 & & & \\
\hline Antidementive Therapy (\%) & 34.0 & 50.5 & 34.0 & 35.8 & $.035 *$ & & \\
\hline Donepezil (\%) & 2.1 & 5.2 & 4.7 & 5.7 & & & \\
\hline Rivastigmine (\%) & 4.1 & 6.2 & 2.8 & 2.8 & & & \\
\hline Galantamine (\%) & 9.3 & 15.5 & 13.2 & 7.5 & & & \\
\hline \multirow[t]{3}{*}{ Memantine (\%) } & 20.6 & 25.8 & 17.9 & 19.8 & & & \\
\hline & & & & & \multicolumn{3}{|c|}{ Effects by ANOVA } \\
\hline & $\mathrm{BL}$ & $\mathrm{FU}$ & $\mathrm{BL}$ & FU & $\begin{array}{l}\text { Group } \\
F(p)\end{array}$ & $\begin{array}{l}\text { Time } \\
\text { F (p) }\end{array}$ & $\begin{array}{l}\text { Group*Time } \\
\text { F(p) }\end{array}$ \\
\hline Qol-AD, mean (SD) & $33.6(4.9)$ & $33.9(5.6)$ & $33.0(4.8)$ & $33.7(5.7)$ & $0.65(0.423)$ & $1.57(0.211)$ & $0.32(.572)$ \\
\hline \multicolumn{8}{|l|}{ CAREGIVER } \\
\hline Hours per day, mean (SD) & $8.5(8.6)$ & $10.3(9.5)$ & $6.4(6.3)$ & $10.5(9.9)$ & $0.14(0.712)$ & $2.84(0.095)$ & $1.77(0.187)$ \\
\hline EQ-5D, VAS, mean (SD) & $72.8(18.6)$ & $70.9(18.9)$ & $70.7(18.9)$ & $70.4(18.9)$ & $0.69(0.407)$ & $0.12(0.734)$ & $0.32(0.963)$ \\
\hline \multicolumn{8}{|l|}{ SF-36 health survey } \\
\hline Physical health sum score, mean (SD) & $48.0(11.2)$ & $46.5(11.6)$ & $46.2(12.7)$ & $43.9(13.2)$ & $1.61(0.207)$ & $0.12(0.912)$ & $0.38(0.536)$ \\
\hline Mental health sum score, mean (SD) & $47.9(13.5)$ & $52.4(10.1)$ & $50.4(10.8)$ & $52.3(10.0)$ & $4.01(0.047)^{*}$ & $0.31(0.577)$ & $2.26(0.134)$ \\
\hline
\end{tabular}

${ }^{*} \mathrm{p}<0.05$; intra-group comparison: McNemar-test, inter-group comparison: chi-squaretest,

$\mathrm{BL}=$ Baseline, $\mathrm{FU}=$ Follow up; NAA $=$ Nuremberg Altersinventar; IADL $=$ Lawtons instrumental activities of daily life VAS= Visual Analog Scale.

respectively, with a highest possible score of 52 . The average score in male was slightly higher than in female, and was slightly lower the stronger the severity of dementia was. Both tendencies however did not reach statistical significance.

On the visual analog scale (VAS) of the EQ-5D persons with dementia score their health status between ,0“ (worst possible) to " $100 "$ (best possible). In this study they indicated their health status on a medium level of mean= $59.2(\mathrm{SD}=17.5)$ and $60.3(\mathrm{SD}=23.6)$, respectively, in the two groups. Neither the intervention $(\mathrm{F}=1.319 ; \mathrm{p}=0.252)$ nor time $(\mathrm{F}=1.497 ; \mathrm{p}=0.223)$ did change this condition.

Sex and age were covariates of perceived health status. Persons with severe dementia rated their health status the 
lowest $(\mathrm{m}=53.9 ; \mathrm{SD}=22.98)$. Comparing the values assessed in this study to the age and sex specific norm values for the German's general population [14], it is shown that people with dementia rate their health worse than people without dementia.

\section{Caregiver Burden}

The BIZA-D measures caregiver burden differentiating objective care tasks and subjective burden. An ANCOVA series with 4 scales for care tasks, 6 subscales for subjective burden and 6 subscales for conflict of needs as interacting dependent variables revealed just a few differences, but no statistical significant differences. Perceived burden increased slightly in both the intervention and the control group. Burden due to challenging behavior did not differ, while burden due to disoriented behavior or depression decreased in the intervention group ( $\mathrm{p}=0.046$ and $\mathrm{p}=0.049$, respectively).

\section{Caregiver's Health Related Quality of Life}

The majority of caregivers $(58.2 \%)$ rated their health status as "good" on a 5-point scale (excellent, very good, good, suboptimal, and bad). A quarter described it as rather not good, 5\% as bad, and about $11 \%$ specified excellent or very good subjective health.

According to the SF-36 physical health was on average rated $\mathrm{m}=47.3(\mathrm{SD}=12.4)$, mental health was rated as $\mathrm{m}=$ $49.2(\mathrm{SD}=11.8)$ on average. Like in other studies in the IDemUck-study the older patients tend to score lower on the physical health scale but higher on the mental health scale, but only the results for the physical health scores met statistical significance $(p<0.01)$. In comparison to the general population the caregiver scored significantly lower on physical as well as mental health (physical health: 47.3, $\mathrm{SD}=12.4$ vs. 50.2, $\mathrm{SD}=10.2 ; \mathrm{p}<0.001$; mental health: $49.2, \mathrm{SD}=11.8$ vs. $51.5, \mathrm{SD}=8.1 ; \mathrm{p}<0.001)$.

Looking at the physical health sum score, caregivers indicated a decrease in the intervention and in the control group $(\mathrm{F}=0.38 ; \mathrm{p}=0.536)$. Mentioning mental health the sum score increased over time and to a greater extent in the intervention group, differences between the groups at baseline $(\mathrm{F}=4.01 ; \mathrm{p}=0.047)$ were compensated. However, ANOVA analyses revealedfor mental health and physical health no significant treatment-by-time effect.

\section{EQ 5-D}

There were ,no problems" indicated in 4 out of 5 dimensions of health-related quality of life by $75 \%$ of the caregivers. Only at the dimension ,pain/discomfort“, $51.1 \%$ of the caregivers reported moderate complaints and 5\% severe complaints. On average, the caregivers rated their health with $\mathrm{m}=71.3(\mathrm{SD}=19.4)$ on the $0-100$ scale. The value decreased significantly by age $(\mathrm{p}<0.01)$. In comparison to the general population values estimated by Hinz and colleagues [14] the caregivers scored significantly lower (71.3 vs. 77.1, $\mathrm{SD}=17.8 ; \mathrm{p}<0.01)$.

While the health score did not change over time in the control group (70.4; $\mathrm{SD}=18.9)$, there was a slight decrease in the intervention group (baseline 72.8 ( $\mathrm{SD}=18.6$ ), follow-up $70.7(\mathrm{SD}=18.9))$. Calculating a variance analyses with repeated measurements, this trend could not be validated.
None of the main effects for treatment, time and interaction did reach statistical significance.

\section{DISCUSSION}

The evaluated Dementia Network represent a type of networking based on clearly defined roles for the GP and other service providers, who together constitute a regional dementia care management. In international trials collaborative care for dementia patients in primary care had demonstrated its effectiveness $[21,22]$. Yet the proof for the specific context of the German health care system is almost completely lacking. To our knowledge, our study was the first network evaluation there, which was based on a prospective randomization. Patients were assigned to either the intervention group or the control group depending on their GP's membership status in the network.

So this paper represents one of the first studies to scientifically evaluate a dementia network in a controlled prospective trial in Germany. Effects were controlled for parameters representing (a) utilization of medical treatment and care, (b) dementia-specific medication, (c) the quality of life of the patients, and (d) the secondary endpoints caregiver burden and health-related quality of life.

The main result of this analysis is that the management of dementia patients in a multi-professional network provides measurable advantages with respect to referral to a specialist and the provision of dementia-specific medication. However, effects on patients' autonomy and health-related quality of life or caregiver burden did not reach statistical significance.

\section{Network Force}

The Uckermark network defined local pathways in primary care to coordinate treatment by GP and specialists from diagnostic workup to follow-up care in the course of disease. In the whole a higher rate of consulting a GP characterize the network treated patients. More patients in an earlier stage of cognitive impairment visited a neurologist/psychiatrist in the case of network treatment. However, neither a specialist referral is recommended in principal nor the rates are equated with diagnostic uncertainty following a standard workup [23]. Under a scenario of GP's running to capacity, a combined treatment of GP and specialist in the period differential diagnosis taking place is indicated. A higher proportion consulting a neurologist/psychiatrist was effective also for PwD potentially being treated by network algorithm a fairly long time, indicating combined treatment in the course of disease.

The prescription of non-pharmacologic therapies remains at a low level and did not significant differ between network care and care as usual. Unscheduled hospital visits are exceptional cases and in no study arm an improvement could be noticed. Even though network structures unite various professions the obstacles among medical and psychosocial services in the community seem to be large, and pharmacotherapy as a first line of action in dementia therapy was chosen [24]. Divergence was found in the prescription of pharmacological therapy, which was established more often in the intervention group. With respect to antidementive drugs the network treatment implied a greater likelihood to put recommendations of dementia guidelines into practice. 


\section{Benefits for Patient and Caregiver}

Benefits in this study were considered in terms of quality of life and improved caregiver burden. The evaluation does not provide evidence for a stronger maintenance in patient's autonomy. However, a systematical review reported an improvement just about $50 \%$ of the selected nonpharmacological intervention studies [25]. According to a review by Cooper and colleagues pharmacological intervention by oneself neither does improve global health-related quality of life [26]. The utilization of patients in the intervention and the care as usual group, respectively, differed solely in some aspects and conditions in dementia health care. Yet in California for example a randomized controlled trial has shown positive effects of a disease management intervention on patients' health-related quality of life [21]. In Germany there is no empirical evidence yet, however there are hints in the literature relating to integrated health care as well as from experience that changes can be made [27].

In the case of secondary outcomes there was a tendency towards a reduction of caregiver burden in this study which did not reach statistical significance. Other studies have also shown small effects of disease management intervention on caregiver burden $[21,28-30]$. One limitation of the IDemUck study could be the restricted time frame of the study with a follow-up of only 1 year being too short to show an effect of participating in a network on effectively improving quality of life. Another prospective trial in German health care system implementing initial case management in regional dementia care could not improve effects on caregiver distress, quality of life, and mood after the intervention time of six month, too [31].

\section{Limitations}

Nevertheless the study has weaknesses that merit comment. The evaluation has been conducted in a routine health care setting and recruitment numbers were limited by the network-size as well as the readiness of patients to participate. In the result the recruiting phase has to be stretched and the time between first and second examination differed significantly between participants. In average patients and caregivers belonging to the intervention group were assessed later for follow-up than those in the control group. In according with adjusted analyses this difference might weigh little, however, the real influence on the consequences of disease as well as the treatment remains unclear. The patients might experience progressive decline in cognition and functioning over time, placing increased burden on informal caregivers.

The binding of the participants was strong and the dropout rates were low. Remarkable are the drop-outs due to withdrawn consent restricted to the intervention group. The reasons are not documented, yet this might lead to some bias in the case the drop-outs are associated with more strain and dissonant outcome.

Eligible persons for the evaluation study were identified by dementia screening, and included patients with a prior diagnosis of dementia as well. Such procedures likely impress usual practice both in intervention and in control group. The impact of the network algorithms on the detection rate of dementia could not be estimated.
Positive impact of intervention takes some time to emerge. However, the timeline of funding limited the followup period to 12 months after baseline. While one year is a standard period in prospective studies, it might be too short to measure the full effects of an intervention that is laid out to be continuous. Furthermore, too little is known about the dynamics during the 12 months. For example: people in the intervention group visit specialists more often. This might cause more strain in the beginning since daily life and its circumstances change. Waiting for appointments with physicians in combination with hesitation to change things and the subsequent changes in diagnosis and treatment might have antagonized the positive impact of the network algorithm particularly in the first months of the study [32-33]. Further studies should therefore examine the changes during interventions over longer follow-up periods.

The comparison with a care as usual control group is rarely in the evaluation of dementia network effects on medical treatment and quality of life, and is counted among the strengths of the study. However, the spatial contiguity of intervention and controls conditions might entail some spillover effects in medical care. These would influence the variance between groups and may diminish the anticipated proceeds.

The provided research context did not comprise further process evaluation. The present lack of defined key components of collaborative models in the specific context of health care system [34] might entail structures and covenants in the analyzed dementia network being realized fragmentarily. Both conditions may interfere with comparative evaluation.

\section{CONCLUSION}

Alzheimer's disease and dementia affect the patient's whole life. The multifaceted consequences of disease demand the involvement of various health professions and disciplines. Interface problems between general and specialized medical care, in- and outpatient sector, medical and social community based services often bar an optimal patientorientated, coordinated and continuous health care, Previous evidence suggests that Dementia Networks can be important structures to improve integration of dementia care in a region. However, in this study merely some outcome measures distinguished collaborative care from care as usual. More evidence is needed particularly from analytic studies and intervention trials in epidemiology of health care contexts. This is especially important because the costs for collaborative care or the type of network described here are not covered in the current health care system in Germany. While voluntary work, such as that employed in IDemUck, is likely an advantage with respect to motivation, it is potentially unsustainable and the potential benefits will likely be restricted to the patients who happen to live in the catchment areas of one of the limited number of projects.

The selected network installs the GP as gatekeeper to the health care system, and the person to join treatment in the medical and behavioral aspects of dementia. Evaluation research should include a variety of networks to identify relevant mechanisms underlying these networks structures and processes with respect to their impact on patient and care- 
giver related outcomes. Furthermore, more research is needed to quantify specific dimensions in the individual treatment plans with desired outcomes. There might be differences in the specific outcomes certain types of networks are able to deliver. There is a need to establish a taxonomy of networks based on defined parameters including aim of the network, members, structures and logistics, target group, setting interventions delivered.

\section{CONFLICT OF INTEREST}

The evaluation study was funded by the Federal Ministry of Health, Germany (Support Code: IIA5-2508FSB013).

\section{ACKNOWLEDGEMENTS}

This paper could not have been written without the support of the IDemUck study team Schwedt, including Prof. Dr. Rüdiger Heicappell, Alain Nguento, Anna Christoforidou and Jacqueline Zühlke, the study team Angermünde, including Dr. Martin Sandner, Annika Löbsin, Melanie Gerlach and Kerstin Gahl, and the scientists at the University of Greifswald, especially Claudia Berlin, and Stefan Weiß.

\section{LIST OF ABBREVIATIONS}

$$
\begin{array}{ll}
\text { BIZA-D }= & \begin{array}{l}
\text { Berlin Inventory of Caregivers' Burden with } \\
\text { Dementia Patients }
\end{array} \\
\text { EQ-5D }= & \begin{array}{l}
\text { EuroQol Group generic measure of health } \\
\text { status }
\end{array} \\
\text { GP } & \text { General Practitioner } \\
\text { MMSE }= & \text { Mini Mental State Examination } \\
\text { NAA }= & \text { Nürnberger-Alters-Alltagsskala } \\
\text { NAI }= & \text { Component of the Nuremberg Inventory of } \\
\text { PwD }= & \text { person with dementia } \\
\text { QoL-AD }= & \text { Quality of Life in Alzheimer's disease } \\
\text { SF-36 }= & \text { Short Form-36 Health Survey } \\
\text { VAS }= & \text { Visual Analog Scale }
\end{array}
$$

\section{REFERENCES}

[1] Ziegler U, Doblhammer G. Prevalence and incidence of dementia in Germany--a study based on data from the public sick funds in 2002. Gesundheitswesen 71(5): 281-290 (2009).

[2] Lobo A, Launer LJ, Fratiglioni L, Andersen K, Di Carlo A, Breteler MM, et al. Prevalence of dementia and major subtypes in Europe: A collaborative study of population-based cohorts. Neurology 54(11): S4-9 (2000).

[3] Siewert U, Fendrich K, Doblhammer-Reiter G, Scholz RD, SchuffWerner P, Hoffmann W. Health care consequences of demographic changes in Mecklenburg-West Pomerania: projected case numbers for age-related diseases up to the year 2020, based on the Study of Health in Pomerania (SHIP). Dtsch Arztebl 107(18): 328-334 (2010).

[4] Hampel H, Prvulovic D, Teipel S, Jessen F, Luckhaus C, Frölich L, et al. The future of Alzheimer's disease: The next 10 years. Prog Neurobiol 95: 718-728 (2011).

[5] Siewert U, Fendrich K, Markus MRP, Baumeister SE, Doblhammer-Reiter G, Scholz RD, et al. Future outpatient health-care utilisation in an ageing population: projections up to the year 2020 based on the Study of Health in Pomerania (SHIP). J Public Health Advance Access published January 3, doi: 10.1007/s10389-0120550-7 (2013).
[6] Alzheimer's Association. Alzheimer's disease facts and figures Alzheimers Dement 8(2): 131-168 (2012).

[7] Bundesministerium für Familie, Senioren, Frauen und Jugend Vierter Bericht zur Lage der älteren Generation. Berlin: BMFSFJ (2002).

[8] Thyrian J, Dreier A, Fendrich K, Lueke S, Hoffmann W. Demenzerkrankungen - Wirksame Konzepte gesucht [Dementia-effective concepts needed]. Dtsch Arztebl 108(38): 1954-1956 (2011).

[9] Ihl R. Integrative Demenzbehandlung. Neurogeriatrie 8(1): S15-6 (2011).

[10] Schaefer-Walkmann S, Deterding D. Integrierte Demenzversorgung in Oberbayern. Stuttgart: InstitutfürangewandteSozialwissenschaften (2010).

[11] Kalbe E, Kessler J, Calabrese P, Smith R, Passmore AP, Brand M, et al. DemTect: a new, sensitive cognitive screening test to support the diagnosis of mild cognitive impairment and early dementia. Int J Geriatr Psychiatry 19: 136-43 (2004).

[12] Logsdon RG, Gibbons LE, McCurry SM, Tery L. Quality of Life in Alzheimer's Disease: Patient and Caregiver Reports. J Ment Health Aging 5: 21-32 (1999).

[13] Hinz A, Klaiberg A, Brähler E, König HH. Der Lebensqualitätsfragebogen EQ-5D: Modelle und Normwertefür die Allgemeinbevölkerung [The Quality of Life Questionnaire EQ-5D: modelling and norm values for the general population]. Psychother Psychosom Med Psychol 56: 42-48 (2006).

[14] Bullinger M, Kirchberger I. SF-36, Fragebogen zum Gesundheitszustand.Göttingen: Hogrefe (1998)

[15] Lawton MP, Brody EM. Assessment of Older People: SelfMaintaining and Instrumental Activities of Daily Living. Gerontologist 9(3): 179-86 (1969).

[16] Oswald WD, Fleischmann UM. Nürnberger-Alters-Alltags-Skala (NAA): Das Nürnberger Altersinventar (NAI). Göttingen: Hogrefe (1997)

[17] Zank S, Schacke C, Leipold B. Berliner Inventar zur Angehörigenbelastung-Demenz (BIZA-D). Z Klein Psychol Psychother 35: 296-305 (2006).

[18] Folstein MF, Folstein SE, McHugh PR. Mini-Mental State.A practical method for grading the cognitivestate of patients for the clinican. J Psychiatr Res 12: 189-198 (1975).

[19] Deutsche Gesellschaft für Psychiatrie, Psychotherapie und Nervenheilkunde (DGPPN); Deutsche Gesellschaft für Neurologie (Eds). Diagnose- und Behandlungsleitlinie DemenzReihe: Interdisziplinäre S3-Praxisleitlinien. Berlin: Springer (2010).

[20] Winkler J, Stolzenberg H. Adjustierung des Sozialen-Schicht-Index für die Anwendung im Kinder- und Jugendgesundheitssurvey (KiGGS) 2003/2006. Wismar Discussion Papers 7 (2009).

[21] Vickrey BG, Mittman BS, Connor KI, Pearson ML, Della Penna $\mathrm{RD}$, Ganiats TG, et al. The effect of disease management intervention on quality and outcomes of dementia care: a randomized, controlled trial. Ann Intern Med 145: 713-26 (2006).

[22] Callahan CM, Boustani MA, Unverzagt FW, Austrom MG, Damush TM, Perkins AJ, et al. Effectiveness of collaborative care for older adults with Alzheimer disease in primary care. JAMA 295: 2148-2157(2006).

[23] Geldmacher DS, Kerwin DR. Practical Diagnosis and Management of Dementia Due to Alzheimer's Disease in the Primary Care Setting: An Evidence-Based Approach. Prim Care Companion CNS Disord 15(4): pii: PCC.12r01474 (2013)

[24] Cantegreil-Kallen I, Turbelin P, Angel A, Flahault, Rigaud AS Dementia management in France: Health care and support services in the community. Dementia 5(3): 317-326 (2006).

[25] McLaren AN, Lamantia MA, Callahan CM. Systematic review of non-pharmacologic interventions to delay functional decline in community-dwelling patients with dementia. Aging Ment Health 17: 655-666 (2013).

[26] Cooper C, Mukadam N, Katona C, Lyketsos CG, Blazer D, et al. Systematic review of the effectiveness of pharmacological interventions to improve quality of life of people with dementia. Am J Geriatr Psychiatry 21: 173-183 (2013).

[27] Sander K, Albus M. Innovative Projekte im Gefolge der Gesundheitsmodernisierungsgesetze: Erfahrungen mit einem Projekt der integrierten Versorgung in der Psychiatrie. Psychiatrische Forschung Suppl 1: 92-5 (2010).

[28] Corbett A, Stevens J, Aarsland D, Day S, Moniz-Cook E, et al. Systematic review of services providing information and/or advice 
to people with dementia and/or their caregivers. Int J Geriatr Psychiatry 27: 628-26 (2012).

[29] Schoenmakers B, Buntix F, DeLepeleire J. Supporting the dementia family caregiver: the effect of home care intervention on general well-being. Aging Ment Health 14: 44-56 (2010).

[30] Newcomer R, Yordi C, DuNah R, Fox P, Wilkinson A. Effects of the Medicare Alzheimer's Disease Demonstration on caregiver burden and depression. Health Serv Res 34: 669-89 (1999).

[31] Lukas A, Kilian R, Hay B, Muche R, von Armin CAF, Otto M, et $a l$. Maintenance of health and relief for caregivers of elderly with dementia by using "inital case Management". Z Gerontol Geriatr 45: 298-307 (2012)

[32] Beard RL. In their voices: identity preservation and experiences of Alzheimer's disease. J Aging Stud 18: 415-428 (2004).

[33] Carpenter BD, Xiong C, Porensky EK, Lee MM, Brown PJ, et al. Reaction to a dementia diagnosis in individuals with Alzheimer's disease and mild cognitive impairment'. J Am Geriatr Soc 56: 405412 (2008).

[34] Reuben DB, Roth C, Kamberg C, Wenger NS. Restructuring primary care practices to manage Geriatric Syndromes: The ACOVE2 Intervention. J Am Geriatr Soc 51: 1787-1793 (2003). 